\title{
A REVIEW ON ZIGBEE, GSM AND WSN BASED HOME SECURITY BY USING EMBEDDED CONTROLLED SENSOR NETWORK
}

\author{
Anjali Kulkarni and Amol Patange \\ Department of Electronics and Telecommunication Engineering, S.R.T.M \\ University,Nanded,
}

\begin{abstract}
Embedded controlled detector network is that the technology needs to implement environmental solutions effectively. The wireless sensor network is used to control respective devices and monitor environmental parameters effectively. Wireless sensor network technology is used to monitor environmental parameters such temperature sound pressure in many applications. Many researchers are developed the wireless sensor network to implement real time surveillance for many applications. The existing wired systems are bulky, very high cost and difficult to maintain. The proposed system is user friendly, low cost and controlled by embedded controlled sensor network. In the proposed system ARM based microcontroller is used for monitoring and wireless sensors are used to control the various devices.
\end{abstract}

\section{KEYWORDS}

Zigbee, GSM, WSN, and Embedded controlled sensor network.

\section{INTRODUCTION}

Wireless sensor networks (WSN) are mainly designed for the specific applications so that the energy harvesting is required. The battery-powered WSN nodes demand battery life over several months or even a few years. The wireless available technologies are Bluetooth, Wi-Fi, Wi-Max, wireless HART, Bluetooth and Zigbee. Wireless sensor networks are formed to communicate wireless links without using a fixed network and controlled by microcontroller. Embedded sensor network and device control improve quality of life of senior citizens and physical disable peoples. It gives a new level of home security and it can also manage the energy harvesting effectively which is promotes the power saving. In addition to remote control, monitoring temperature, LPG gas, humidity in homes is also a major concern.

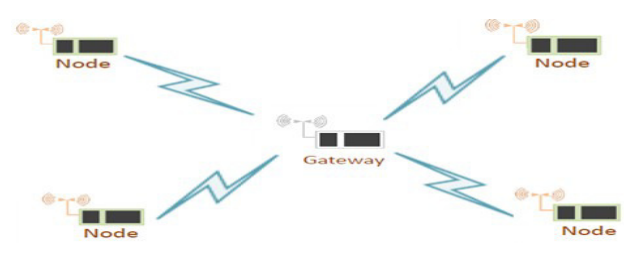

Figure No. 1 System Architecture

DOI: $10.5121 /$ ijesa.2016.6401 


\section{Methodology}

In this existing wireless system, we have designed one master module which consists of arm7 microcontroller, GSM module and Zigbee module. The slave module is designed using AVR microcontroller and Zigbee module, GSM module is used for long distance communication. The GSM module uses AT commands to send the SMS on house owner mobile phone. Zigbee technology is used for wireless personal area networking. Zigbee technology is very simple and low cost, easy to construction with wireless technology. In this paper we can monitor the Fire, Gas and Humidity by using fire sensor, gas sensor and humidity sensor. Here fire sensor, gas sensor and humidity sensor will measure the temperature, gas concentrations in air and humidity in air. When above parameters exceeds its appropriate value the embedded system control the respective device and also send the SMS through GSM to Mobile.

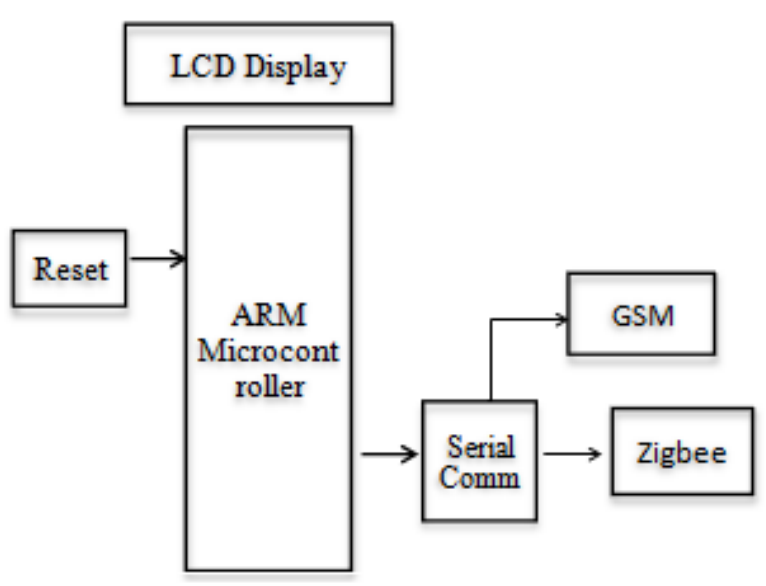

Figure No. 2 Master Node

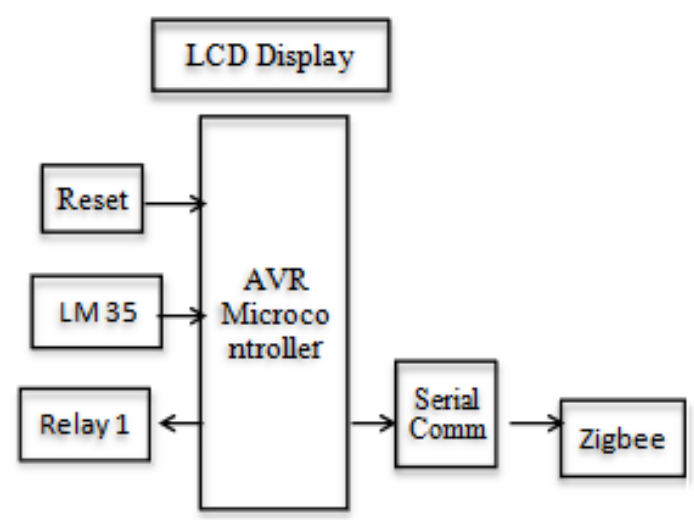

Figure No. 3 Slave Node 1 


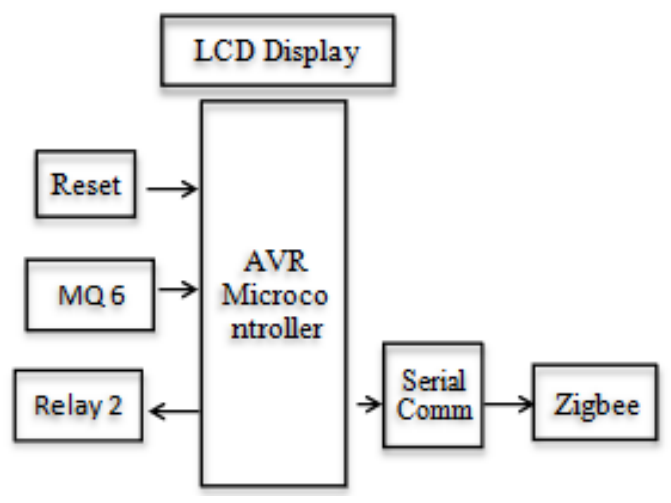

Figure No. 4 Slave Node 2

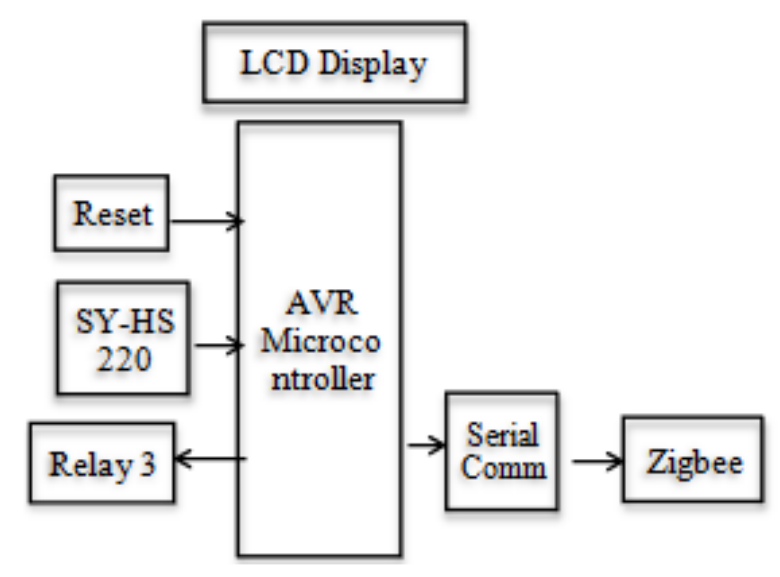

Figure No. 4 Slave Node 3

\section{The Major Weaknesses Of EXisting Wireless System}

1.In above existing wireless system, slave node 1 used LM35 temperature sensor for fire detection. This temperature sensor suffers from thermal lag when fires build quickly. "Thermal lag" occurs when rapid temperature increases. It causes the temperature detector to alarm at a temperature higher than its set point.

2.Temperature sensor can give false alarm if the installation environment temperature changes naturally and rapidly to the ambient temperature. Temperature detectors are minimizing the property damage by responding to the change in temperature due to fire.

3.The above system does not detect the cause of fire generation, due to short circuit or not.

4. When LPG gas leakage is detected by the system exhaust fan is turn ON. A single spark of exhaust fan is dangerous to ignition of fire. 


\section{Proposed System}

In this paper, in proposed system we use smoke detector instead of LM35 temperature detector. Earlier in the development of a fire smoke detectors are generating an alarm to protect people and property. Incomplete combustion causes by smoldering fires or burn very slowly without flames fire, which is generates more smoke, poisonous gases. Very little heat is generated by smoldering fires which is difficult to detect with temperature detectors. During a fire people are mostly harmed due to smoke and poisonous gases and not harmed due to heat or flames. Therefore in this paper smoke detector is used as fire sensor instead of temperature sensor.

In this paper, in LPG gas detection module DC motor and Solenoid valves are used instead of exhaust fan. DC motor is used to open the window and solenoid valve is used to block the LPG gas pipe to prevent gas leakage from pipe. The proposed system detects the cause of fire generation due to electrical short circuit or not. If fire is generated due to short circuit then we cannot use water as fire extinguisher because water is good conductor of electricity.

\section{Avr Microcontroller}

\subsection{WHY AVR?}

AVRs can be used in various applications such as home security, safety, and automation. Atmega16 cannot require pull-up registers whereas 8051 required pull-up resistors.Atmega16 has RISC instruction set, most of instructions are executed in single cycle, while 8051 has CISC which require multiple machine cycles for execution.Atmega 16 has peripherals like 8 and 16 bits timers. Atmega16 has 8-channel 10 bit ADCs,I2C bus, SPI bus, UART interface, watchdog timer, while 8051 only has 2 timers plus UART and SPI. Atmega16 has higher code memory and RAM as compare to 8051 . Atmega16 is simple to program and easy to learn and use. One big difference is the AVR is much faster than 8051. It executes most instructions in a single clock cycle than 8051 .

\subsection{The Atmega16 Provides The Following Features}

16K bytes of In-System Programmable Flash Program memory with Read-While-Write capabilities, 512 bytes EEPROM, 1Kbyte SRAM, 32 general purpose I/O lines, 32 general purpose working registers, a JTAG interface for Boundary-scan, On-chip Debugging support and programming, three flexible Timer/Counters with compare modes, Internal and External Interrupts, a serial programmable USART, a byte oriented Two-wire Serial Interface, an 8channel, 10-bit ADC with optional differential input stage with programmable gain (TQFP package only), a programmable Watchdog Timer with Internal Oscillator, an SPI serial port, and six software selectable power saving modes. The Idle mode stops the CPU while allowing the USART, Two-wire interface, A/D Converter, SRAM; Timer/Counters, SPI port, and interrupt system to continue functioning. In Power-save mode, the Asynchronous Timer continues to run, allowing the user to maintain a timer base while the rest of the device is sleeping. The ADC Noise Reduction mode stops the CPU and all I/O modules except Asynchronous Timer and ADC, to minimize switching noise during ADC conversions. In Standby mode, the crystal/resonator 
Oscillator is running while the rest of the device is sleeping. This allows very fast start-up combined with low-power consumption. In Extended Standby mode, both the main Oscillator and the Asynchronous Timer continue to run.

\section{ARM Microcontroller LPC 2138}

LPC 2138 microcontrollers are based on a 16-bit/32-bit ARM7TDMI-S CPU with real-time emulation and embedded trace support, that combine microcontroller with embedded high speed flash memory ranging from $32 \mathrm{kB}$ to $512 \mathrm{kB}$. A 128-bit wide memory interface and unique accelerator architecture enable 32-bit code execution at the maximum clock rate. For critical code size applications, the alternative 16-bit Thumb mode reduces code by more than $30 \%$ with minimal performance penalty. Due to their tiny size and low power consumption, LPC 2138/36 are ideal for applications where miniaturization is a key requirement, such as access control and point-of-sale. LPC 2138 has serial communications such as USB 2.0 Full-speed device, multiple UARTs, SPI, SSP to I2C-bus and on-chip SRAM. Various 32-bit timers, single or dual 10-bit ADC(s), 10-bit DAC, PWM channels and 45 fast GPIO lines with up to nine edge or level sensitive external interrupt pins make these microcontrollers suitable for industrial applications and medical application.

\section{GSM OVERVIEW}

Global System for Mobile Communications (GSM) is a TDMA based cell phone technology used in Europe and different parts of the world. First GSM based mobile services are launched in Finland in 1991. Now a day GSM networks operate on different frequency band $850 \mathrm{MHz}$, $900 \mathrm{MHz}, 1800 \mathrm{MHz}$ and $1900 \mathrm{MHz}$. GSM modem used AT commands for sending and receiving SMS messages in Sim. In this paper we use SIM 900 GSM Module which having following specifications; Quad Band GSM: 850 / 900 / 1800 / 1900 MHz Dimensions: 24* $24 * 3$ mm. Weight: $3.4 \mathrm{gm}$. Operation temperature: $-30{ }^{\circ} \mathrm{C}$ to $+80{ }^{\circ} \mathrm{C}$. Control via AT commands. Input Voltage: 5V to $12 \mathrm{~V}$ DCSIM 900 Quad-band GSM/GPRS engine works on frequencies $850 \mathrm{MHz}$, $900 \mathrm{MHz}, 1800 \mathrm{MHz}$ and $1900 \mathrm{MHz}$. It is very compact in size and easy to use as plug in GSM Modem. The Modem is designed with RS232 Level converter circuitry, which allows you to directly interface PC Serial port. The baud rate can be configurable from 9600-115200 through AT command. Initially Modem is in Auto baud mode. This GSM/GPRS RS232 Modem is having internal TCP/IP stack to enable you to connect with internet via GPRS. It is suitable for SMS as well as DATA transfer application in M2M interface.

\section{Zigbee, A Technical OvervieW OF Wireless Technology}

\subsection{WHAT IS WIRELESS SENSOR NETWORK?}

Wireless sensor network (WSN) is a group of sensors for monitoring and recording the physical conditions of the environment and organizing the collected data at a central location. WSNs measure environmental conditions like temperature, sound, pollution levels, humidity, wind speed and direction, pressure, etc. 
International Journal of Embedded systems and Applications (IJESA) Vol.6, No.3/4, December 2016

\subsection{WHY WIRELESS?}

Avoid lot of wiring. It saves installation costs. It can accommodate new device any time. It is self-organized network. It is Low power and low cost.

\subsection{What Is Zigbee?}

Zigbee operates in the industrial, scientific and medical (ISM) radio bands; $868 \mathrm{MHz}$ in Europe, $915 \mathrm{MHz}$ in the USA and Australia, and $2.4 \mathrm{GHz}$ in worldwide. Zigbee is an open global standard for wireless technology and operates on the IEEE 802.15.4 specification designed to use lowpower digital radio signals for personal area networks. Zigbee can automatically establish its network. It supports up to 65,000 nodes connected in a network. Zigbee is a wireless network technology used for remote control and sensor applications which is suitable for operation in harsh environments. It builds on IEEE standard 802.15.4 which defines the physical and MAC layers.

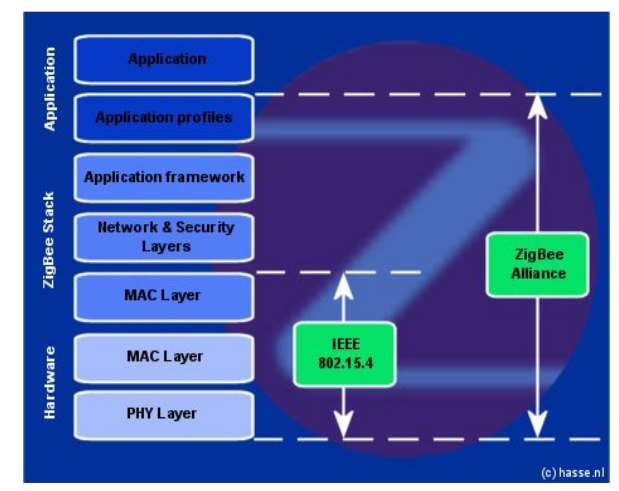

Figure No. 5 Physical, application and MAC Layer of zigbee

The most important feature of zigbee is Low power consumption therefore battery operated devices operate for a long time. The distance between nodes can be up to 50 meters. Hardware (Physical and MAC layers) at the moment all solutions work on $2.4 \mathrm{GHz}$ but specified is also $915 \mathrm{MHz}$ for North America and $868 \mathrm{MHz}$ for Europe. The $2.4 \mathrm{GHz}$ frequency band is a license free band and used all over the world. All current products seem to be using the $2.4 \mathrm{GHz}$ band at the moment. Following table shows frequency difference between the bands used in different area:

Table1. Frequency Assignment

\begin{tabular}{|l|c|c|c|}
\hline Geographical regions & Europe & Americas & Worldwide \\
\hline Frequency assignment & $\begin{array}{c}868 \text { to } 868.6 \\
\mathrm{MHz}\end{array}$ & $\begin{array}{c}902 \text { to } 928 \\
\mathrm{MHz}\end{array}$ & $\begin{array}{c}204 \text { to } \\
2.4835 \mathrm{GHz}\end{array}$ \\
\hline Number of channels & 1 & 10 & 16 \\
\hline Channel bandwidth & $600 \mathrm{KHz}$ & $2 \mathrm{MHz}$ & $5 \mathrm{MHz}$ \\
\hline Data rate & $20 \mathrm{kbps}$ & $40 \mathrm{kbps}$ & $250 \mathrm{kbps}$ \\
\hline Modulation & BPSK & BPSK & Q-QPSK \\
\hline
\end{tabular}


Direct sequence spread spectrum (DSSS) is used in all bands of zigbee. 868 and $915 \mathrm{MHz}$ frequency bands are used Binary Phase Shift Keying and 2.4GHz frequency band used O-QPSK (Offset Quadrature Phase Shift Keying). These license free frequencies are becoming more and more crowded and noisy. The 802.15.4 specification has many features to ensure a reliable operation under the worst environmental conditions. Some keywords: Clear Channel Assessment, Quality Assessment and Receiver Energy Detection. To prevent problems caused by it, a technique called Carrier Sense Multiple Access (CSMA) is used to only transmit when this does not cause problems (collisions).Like in any network data is transmitted in packets. The maximum size of zigbee packet have128 bytes.

In this paper XB24-Z7WIT-004 Zigbee module is used. Specifications of Zigbee are as follows.

1. Operating Frequency: ISM $2.4 \mathrm{GHz}$

2. Antenna type: Wire antenna

3. Indoor/Urban Range up to $133 \mathrm{ft}$. (40 m)

4. Outdoor RF line-of-sight Range up to $400 \mathrm{ft}$. (120 m)

5. Interface: Serial (UART) at 1200 - 1 Mbps

6. Supply Voltage: $2.1-3.6 \mathrm{~V}$

7. Dimensions: $0.960 "$ x $1.087 "(2.438 \mathrm{~cm} \times 2.761 \mathrm{~cm})$

8. Operating Temperature: -40 to $85^{\circ} \mathrm{C}$ (industrial)

Table 2.Comparison between Zigbee and other Wireless technologies.

\begin{tabular}{|l|l|l|l|}
\hline \multicolumn{1}{|c|}{ Market Name } & \multicolumn{1}{c|}{ Wi-Fi } & \multicolumn{1}{c|}{ Bluetooth } & \multicolumn{1}{c|}{ Zigbee } \\
\hline Standard & $\begin{array}{l}\text { IEEE } \\
802.11 \mathrm{~b}\end{array}$ & IEEE 802.15.1 & IEEE 802.15.4 \\
\hline Application Focus & $\begin{array}{l}\text { Web, Email, } \\
\text { Video }\end{array}$ & $\begin{array}{l}\text { Cable } \\
\text { Replacement }\end{array}$ & $\begin{array}{l}\text { Monitoring and } \\
\text { Control }\end{array}$ \\
\hline Battery Life & Hours & Days & Years \\
\hline Network Size & 32 & 7 & Up to 65536 \\
\hline Range (meters) & $1-100$ & $1-10+$ & $1-100+$ \\
\hline Network Architecture & Star & Star & Star , Tree, Mesh \\
\hline Data rates (K bits/s) & $11,000+$ & 720 & 250 \\
\hline
\end{tabular}

\section{CONCLUSION}

This paper developed a designing of embedded controlled sensor networks used for controlling the home devices and monitoring the environmental parameters. Smoke detector and Temperature detector can detect a fire, but these detectors are actually designed to serve different needs. Temperature detectors are intended to minimize property damage. Therefore temperature detectors are normally used in places where there is high heat and high flames. The temperature detectors are generally used in storage rooms where chemicals, fuels and other properties are stored. This is a cost effective home security system which performs reliably to ensure safety from fire. It can be used to detect burnable LPG gas. It can be used to detect humidity in air. It can be installed in houses, industries, offices, hospitals etc. very easily. The system can be 
International Journal of Embedded systems and Applications (IJESA) Vol.6, No.3/4, December 2016

designed for coverage up to 100 meter area. By installing multiple modules for each floor we can monitor large industrial and residential area. The zigbee and GSM are used for short as well as long distance communication.

\section{REFERENCES}

[I] Burrell, T. Bro A. Camilli, C. E. Cugnasca, A. M. Saraiva, A. R.Hirakawa, and P. L. P. CorrAea. From wireless sensors to field mapping:Anatomy of an application for precision agriculture. Comput. Electron.Agric.,58( I ):25-36,2007.

[2] Guangming Song, Fei Ding, Weijuan Zhang and Aiguo Song, "A Wireless Power Outlet System for Smart Homes," IEEE Transactions on Consumer Electronics, Vol. 54, No.4, November,2008.

[3] Shen Jin, Song Jingling, Han Qiuyan, Wang Shengde, Yang Yan, "A Remote Measurement and Control System for Greenhouse based on GSM-SMS" IEEE 8th International Conference on Electronic Measurement and Instrument, 2007.

[4] G. K. Banerjee, Rahul Singhal, Bhubaneswar, Orissa India "Microcontroller Based Polyhouse Automation Controller", International Symposium on Electronic System Design, pp.158- 162, Dec 2010.

[5] Wen bin Huang, Guanglong Wang, Jianglei Lu, Fengqi Gao,1ianhui Chen "Research of wireless sensor networks for an intelligent measurement system based on ARM",Tnternational conference on Mechatronics and Automation, pp. 1074 - 1079,2011. 